Www.jmscr.igmpublication.org

Index Copernicus Value: 79.54

ISSN (e)-2347-176x ISSN (p) 2455-0450

crossref DOI: https://dx.doi.org/10.18535/jmscr/v7i5.100

Journal Of Medical Science And Clinical Research

IGM Publication

An Official Publication of IGM Publication

Original Research Article

\title{
Incidence and Prevalence of Urinary Tract Infections among Pregnant Women and their Antimicrobial Sensitivity Pattern in Tertiary Care Hospital, at Bettiah, North Bihar
}

\author{
Authors \\ Dr Sanjay Kumar ${ }^{1}$, Dr S. N. Singh ${ }^{2}$, Dr Satyendu Sagar ${ }^{3 *}$ \\ ${ }^{1}$ Tutor, Department of Microbiology, Government Medical College, Bettiah \\ ${ }^{2}$ Professor and HOD, Department of Microbiology, Government Medical College, Bettiah \\ ${ }^{3}$ Assistant Professor, Department of Microbiology, Nalanda Medical College, Patna \\ *Corresponding Author \\ Dr Satyendu Sagar \\ Assistant Professor, Department of Microbiology, Nalanda Medical College, Patna, India
}

\begin{abstract}
Objective: Persistent Urinary tract infections (UTI) in Pregnant Women cause poor maternal and perinatal results. Present study was conducted to evaluate the Incidence and Prevalence of Urinary Tract Infections among Pregnant Women and Their Antimicrobial Sensitivity Pattern in Tertiary Care Hospital.

Materials and Methods: A total of 320 Pregnant Women presented with symptoms of UTI were included in the study. From all the Pregnant Women a total of 320 early morning mid stream voided urine samples were collected in sterile urine pot in fully aseptic methods. All the samples were collected and received to the laboratory without delay for further processing. Routine examination of urine and Culture and sensitivity of samples were done and organism was identified by standard protocol. The organism was isolated and tested for antimicrobial sensitivity pattern by KirbyBauer disc diffusion method, according to CLSI guidelines. Antibiotics disk used are Amoxicillin, Amoxicillin+clavulanic acid, Cephalosporins, Naladixic acid, Nitrofurantoin, Cotrimoxazole, and Ciprofloxacin, Norfloxacin.

Results: Out of 320 pregnant women included for the study, 96 pregnant women (30\%) have symptomatic bacteriuria and 224 pregnant women (70\%) have asymptomatic bacteriuria. The prevalence of bacteriuria among symptomatic and asymptomatic pregnant women were (12.4\%), and (15.2\%) respectively, with no significant difference between the two groups, and the overall prevalence of UTI was (15\%). Age, gestational age, parity, and history of UTI in pregnancy were not associated with bacteriuria. Out of 96 symptomatic pregnant women, 54 isolates were isolated, after culture of urine. Escherichia coli were 32 (59.26\%) and S. aureus $16(29.63 \%)$ were the commonest isolated bacteria, followed by K.Pneumoniae $3(5.56 \%)$, Group B Streptococcus 2 (3.70\%) and Pseudomonas aeruginosa was $1(1.85 \%)$. E. coli isolates, showed resistance to Amoxycillin 5, Naladixic acid 4, Nitrofurantoin 3, Ciprofloxacin5, Co-trimoxazole6, Amoxycillin+Clavulanate 3 and Norfloxacin in 2 isolates.

Conclusion: Escherichia coli were the most prevalent causative organisms and showing multi drug resistance pattern, asymptomatic bacteriuria is more prevalent than symptomatic among pregnant women. During antenatal checkup all the pregnant women is recommended for Urine culture to rule out the symptomatic or asymptomatic bacteriuria so that the complication of pregnancy can be prevented.

Keywords: Urinary Tract Infection, pregnancy, bacteriuria, antibiotic.
\end{abstract}




\section{Introduction}

UTI is defined as infection of the urinary system i.e. kidney, calyx, ureter, bladder, prostate and urethra. $90 \%$ of ambulatory UTI, 25-30\% of hospital and hospital acquired infection (Nosocomial infection) and $85-90 \%$ of uncomplicated cystitis in pre and postmenopausal woman is due to E.Coli. Pregnant womens are more susceptible to develop Urinary tract infections due to anatomical and hormonal changes. UTI is a major public health problem and it has been reported that about $20 \%$ of the pregnant women are admitted to obstetrical wards are due to UTI. $17.9 \%$ pregnant woman has Symptomatic and $13.0 \%$ pregnant women has asymptomatic bacteriuria have been reported.

5-10\% of pregnant woman having UTI without any symptoms called as asymptomatic bacteriuria, if undected or untreated may leads to symptomatic infection. Later on pregnancy pyelonephritis, PIH (pre-eclampsia), prematurity (IUGR) and perinatal death of fetus may occur. Furthermore, pyelonephritis which can lead to acute respiratory distress, transient renal failure, sepsis and shock during pregnancy.

Screening of pregnant women during antenatal checkup for UTI can decrease the UTI and associated complications. Escherichia coli with its multidrug resistant strains have been found to be the commonest cause of UTI among pregnant women.

Thus this was the objective of this study which has been conducted at the tertiary care hospital to rule out asymptomatic bacteriuria in pregnant woman.

\section{Materials and Methods}

Present study was conducted in the Department of Microbiology, Government Medical College, Bettiah, West Champaran, Bihar, with the help of Department of Obstetrics and Gynecology, during the period of February 2018 to February 2019. A total of 320 Pregnant Women presented with symptoms of UTI were included in the study.
Those with known underline renal pathology or chronic renal disease were excluded.

After taking an informed consent, relevant medical, obstetrical and socio demographic characteristics were noted. Maternal hemoglobin was measured from all the Pregnant Women.

From all the Pregnant Women a total of 320 early morning mid stream voided urine samples were collected in sterile urine pot in fully aseptic methods.

Routine examination of Urine specimens was done within an hour of collection, using dipstick methods and then samples were analyzed for culture and sensitivity. By using standard quantitative loop a $1 \mu \mathrm{l}$ and $10 \mu \mathrm{l}$ were used to inoculate urine sample on Nutrient agar plate, Cysteine lactose electrolyte deficient Agar (CLED), Mac Conkey and Blood agar plates. Plates were incubated for $24 \mathrm{hr}$ at $37^{\circ} \mathrm{C}$. At least $10^{5}$ colony forming unit $(\mathrm{CFU}) / \mathrm{ml}$ is required for significant growth. For contaminated specimens, repeat culture was performed.

Identification was done by colonial morphology, Grams staining and biochemical testing. Antibiotic sensitivity test was done by KirbyBauer disc diffusion method according to CLSI guidelines. Antimicrobial discs used are Amoxicillin $(25 \mu \mathrm{g})$, Cotrimoxazole (SXT) $(1.25 / 23.75 \mu \mathrm{g}), \quad$ Nitrofurantoin $(300 \mu \mathrm{g})$, Ciprofloxacin $(5 \mu \mathrm{g})$, Nalidixic acid $(30 \mu \mathrm{g})$, Amoxicillin+Clavulanic acid $(20 \mu \mathrm{g} / 10 \mu \mathrm{g})$, and Norfloxacin $(5 \mu \mathrm{g})$. All the media and chemicals were supplied by HAI media, Mumbai and reading were taken according to CLSI guidelines.

\section{Results}

Out of 320 pregnant women included for the study, 96 pregnant women (30\%) have symptomatic bacteriuria and 224 pregnant women (70\%) have asymptomatic bacteriuria. The prevalence of bacteriuria among symptomatic and asymptomatic pregnant women were $(12.4 \%)$, and $(15.2 \%)$ respectively, with no significant difference between the two groups, and the overall prevalence of UTI was (15\%). Age, gestational 
age, parity, and history of UTI in pregnancy were not associated with bacteriuria. Out of 96 symptomatic pregnant women, 54 isolates were isolated, after culture of urine. Escherichia coli were $32(59.26 \%)$ and S. aureus $16(29.63 \%)$ were the commonest isolated bacteria, followed by K.Pneumoniae 3 (5.56\%), Group B Streptococcus $2(3.70 \%)$ and Pseudomonas aeruginosa was $1(1.85 \%)$.

Table-1 shows Prevalence of bacteriuria in pregnant woman

\begin{tabular}{|l|c|c|}
\hline Symptoms in pregnant woman & Total no. of pregnant woman & Percentage \\
\hline Symptomatic bacteriuria & 96 & 30 \\
\hline Asymptomatic bacteriuria & 224 & 224 \\
\hline TOTAL & 320 & \\
\hline
\end{tabular}

Table -2 shows Bacterial Isolates, isolated in culture

\begin{tabular}{|l|c|c|}
\hline Bacterial Isolates & No. of Isolates & Percentage \\
\hline E. Coli & 32 & 59.26 \\
\hline Staphyllococcus aureus & 16 & 29.63 \\
\hline Klebsiella Pneumoniae & 3 & 5.56 \\
\hline Gr.B Streptococcus & 2 & 3.70 \\
\hline Pseudomonas spp. & 1 & 1.85 \\
\hline TOTAL & 54 & 100 \\
\hline
\end{tabular}

Table-3 Shows Antibiotic Resistance Pattern of Isolates

\begin{tabular}{|l|c|c|c|c|c|c|c|}
\hline Bacterial Isolates & $\begin{array}{c}\text { Amoxy } \\
\text { cillin }\end{array}$ & $\begin{array}{c}\text { Naladixic } \\
\text { acid }\end{array}$ & $\begin{array}{c}\text { Nitrofurantoi } \\
\text { n, }\end{array}$ & $\begin{array}{c}\text { Ciprofloxa } \\
\text { cin, }\end{array}$ & $\begin{array}{c}\text { Co- } \\
\text { trimoxazole }\end{array}$ & $\begin{array}{c}\text { Amoxycillin+Cl } \\
\text { avulanic acid }\end{array}$ & $\begin{array}{c}\text { Norflox } \\
\text { acin, }\end{array}$ \\
\hline E. Coli & 5 & 4 & 3 & 5 & 6 & 3 & 2 \\
\hline $\begin{array}{l}\text { Staphyllococcus } \\
\text { aureus }\end{array}$ & 1 & 7 & 1 & 2 & 2 & 2 \\
\hline $\begin{array}{l}\text { Klebsiella } \\
\text { Pneumoniae }\end{array}$ & 2 & 2 & 0 & 0 & 0 & 2 & 3 \\
\hline Gr.B Streptococcus & 0 & 1 & 0 & 0 & 0 & 0 & 0 \\
\hline Pseudomonas spp. & $\mathrm{R}$ & 0 & $\mathrm{R}$ & 0 & $\mathrm{R}$ & 0 & 0 \\
\hline
\end{tabular}

E. coli isolates, showed resistance to Amoxycillin 5, Naladixic acid 4, Nitrofurantoin 3, Ciprofloxacin 5, Co-trimoxazole 6, Amoxycillin+ Clavulanate 3 and Norfloxacin 2 isolates. S. aureus isoltes showed resistant to amoxicillin (1), norfloxacin (3), Co-trimoxazole (2), and Naladixic acid (7). K. pneumonia isolates have resistance to amoxicillin (2), both Naladixic acid and Amoxicillin+Clavulanic acid (2). There was no resistance to Co-trimoxazole, Nitrofurantoin, Norfloxacin and Ciprofloxacin. Group B streptococcus isolates has resistance to Naladixic acid while sensitive to Amoxicillin, Nitrofurantoin, Amoxicillin+Clavulanate, Norfloxacin, Co-trimoxazole and ciprofloxacin. One $\mathrm{P}$. aeruginosa isolate has resistance to Amoxicillin, Nitrofurantoin, and Co-trimoxazole, while sensitive to Naladixic acid, Ciprofloxacin, Amoxicillin+Clavulanic acid, Norfloxacin.

\section{Discussion}

The main findings of this study were: the prevalence of UTI among pregnant women was $15 \%$ regardless to the women's age, parity and gestational age and E. coli showed resistance to multi drugs. The prevalence of UTI among these women is similar to the prevalence of UTI among pregnant women in the previous study $14.6 \%$ and $11.6 \%$.

Age, parity and gestational age were not associated with UTI in this study but maternal age, parity and obesity have been found as risk factors for UTI among pregnant women. It has been reported that, UTI developed in third 
trimester due to uretral dilatation. Other factors like low socio-economic status, sexual activity, washing genitals precoitus, postcoitus, not voiding urine postcoitus and washing genitals from back to front have observed as risk factors for UTI during pregnancy.

In present study E. coli was the most common pathogen (59.26\%), In Tanzania where E. coli was found to be $38 \%$ and many authors have the same findings e.g. in Pakistan and India.

In present studyE. coli showed multidrug resistance mainly to amoxicillin, co-trimoxazole and nitrofurantoin. In Africa high antimicrobial resistance pattern was reported that, in urinary $\mathrm{E}$. coli isolates. Gales et al and Williams et al have reported high antimicrobial resistance of E. coli in Latin American and Costa Rica.

Although, S. aureus was known for years as rare urinary isolate recently it has been reported to be the most frequent pathogen among pregnant women and it was found the second most prevalent bacteria.

In present study, women who had positive isolate received an antibiotic in pregnancy. It has been shown that antimicrobial resistance to one drug does not always correlate to the consumption of the same drug or closely related drugs. Inappropriate, inadequate, lack of knowledge about drugs and non availability of antimicrobial can leads drug resistance.

\section{Conclusion}

There was high prevalence of asymptomatic bacteriuria among pregnant women. E. coli was the most common isolated organism. Thus urine culture should be advised in the entire woman during antenatal checkup.

\section{Reference}

1. Dafnis E, Sabatini S: The effect of pregnancy on renal function: physiology and pathophysiology. Am J Med Sci. 1992, $303 \quad$ (3): $184-205$. 10.1097/00000441-199203000-00011
2. Bacak SJ, Callaghan WM, Dietz PM, Crouse C: Pregnancy-associated hospitalizations in the United States, 19992000. Am J Obstet Gynecol. 2005, 192 (2): 592-7. 10.1016/j.ajog.2004.10.638

3. Masinde A, Gumodoka B, Kilonzo A, Mshana SE: Prevalence of urinary tract infection among pregnant women at Bugando Medical Centre, Mwanza, Tanzania. Tanzan J Health Res. 2009, 11 (3): 154-9.

4. Mazor-Dray E, Levy A, Schlaeffer F, Sheiner E: Maternal urinary tract infection: is it independently associated with adverse pregnancy outcome?. J Matern Fetal Neonatal Med. 2009, 22 (2): 124-8. 10.1080/14767050802488246

5. Barnick CGW, Cardozo LD: (1991) the lower urinary tract in pregnancy, labour and puerperium.Progress in Obstetrics and Gynaecology. Edited by: Studd J. 9: 195204. London: Churchill Livingston 10.1080/14767050802488246

6. Gilstrap LC, Ramin SM: Urinary tract infections during pregnancy. Obstetrics and Gynaecology Clinics North America. 2001, 28 (3): 581-91. 10.1016/S08898545(05)70219-9.

7. Millar LK, Cox SM: Urinary tract infections complicating pregnancy. Infectious Diseases Clinics of North America. 1997, 11 (1): 13-26. 10.1016/S0891-5520(05)70339-1.

8. Haider G, Zehra N, Munir AA, Haider A: Risk factors of urinary tract infection in pregnancy. J Pak Med Assoc. 2010, 60 (3): 213-6.

9. Dalzell JE, Lefevre ML: Urinary tract infection of pregnancy. American Academy of Family Physicians. 2000, 61 (3): 713-21.

10. Kariuki S, Revathi G, Corkill J, Kiiru J, Mwituria J, Mirza N, Hart CA: Escherichia coli from community-acquired urinary tract infections resistant to 
fluoroquinolones and extended-spectrum beta-lactams. J Infect Dev Ctries. 2007, 1 (3): 257-62.

11. Assefa A, Asrat D, Woldeamanuel Y, G/Hiwot Y, Abdella A, Melesse T: Bacterial profile and drug susceptibility pattern of urinary tract infection in pregnant women at Tikur Anbessa Specialized Hospital Addis Ababa, Ethiopia. Ethiop Med J. 2008, 46 (3): 22735.

12. Murray PR, Baron EJ, Pfaller MA, Tenover FC, Yolken RH: Manual of Clinical Microbiology. 1995, 1482American Society of Microbiology Press, Washington DC, 6. 